\title{
Screening strategies and predictive diagnostic tools for the development of new-onset diabetes mellitus after transplantation: an overview
}

This article was published in the following Dove Press journal:

Diabetes, Metabolic Syndrome and Obesity:Targets and Therapy

25 October 2012

Number of times this article has been viewed

\author{
Phuong-Thu T Pham' \\ Kari L Edling ${ }^{2}$ \\ Harini A Chakkera ${ }^{3}$ \\ Phuong-Chi T Pham ${ }^{4}$ \\ Phuong-Mai T Pham ${ }^{5}$ \\ 'Department of Medicine, Nephrology \\ Division, Kidney Transplant Program, \\ David Geffen School of Medicine \\ at UCLA, Los Angeles, CA, USA; \\ ${ }^{2}$ Department of Medicine, Division \\ of Endocrinology, Diabetes and \\ Hypertension, David Geffen \\ School of Medicine at UCLA, Los \\ Angeles, CA, USA; ${ }^{3}$ Department \\ of Medicine, Nephrology Division \\ Kidney Transplant Program, Mayo \\ Clinic Hospital, Phoenix, AZ, USA; \\ ${ }^{4}$ Department of Medicine, Nephrology \\ Division, UCLA-Olive View Medical \\ Center, Sylmar, CA, USA; ${ }^{5}$ Department \\ of Medicine, Greater Los Angeles, \\ Veterans Administration Health Care \\ System, CA, USA
}

Correspondence: Phuong-Thu T Pham Department of Medicine, Nephrology Division, Kidney Transplant Program, David Geffen School of Medicine at UCLA, Los Angeles, CA 90095, USA

$\mathrm{Tel}+\mathrm{I} 3107941757$

Fax + I 3108256309

Email PPham@mednet.ucla.edu

\begin{abstract}
New-onset diabetes mellitus after transplantation (NODAT) is a serious and common complication following solid organ transplantation. NODAT has been reported in $2 \%$ to $53 \%$ of all solid organ transplants. Kidney transplant recipients who develop NODAT have variably been reported to be at increased risk of fatal and nonfatal cardiovascular events and other adverse outcomes including infection, reduced patient survival, graft rejection, and accelerated graft loss compared with those who do not develop diabetes. Limited clinical studies in liver, heart, and lung transplants similarly suggested that NODAT has an adverse impact on patient and graft outcomes. Early detection and management of NODAT must, therefore, be integrated into the treatment of transplant recipients. Studies investigating the best screening or predictive tool for identifying patients at risk for developing NODAT early after transplantation, however, are lacking. We review the clinical predictive values of fasting plasma glucose, oral glucose tolerance test, and A1C in assessing the risk for NODAT development and as a screening tool. Simple diabetes prediction models that incorporate clinical and/or metabolic risk factors (such as age, body mass index, hypertriglyceridemia, or metabolic syndrome) are also presented.
\end{abstract}

Keywords: new-onset diabetes after transplantation, impaired fasting glucose, impaired glucose tolerance, oral glucose tolerance test, NODAT screening, diabetes prediction models

\section{Introduction}

The development of diabetes mellitus after kidney transplantation attributed to steroid use was first reported by Starlz in 1964, ${ }^{1}$ and subsequently recognized as a complication of kidney transplantation in the 1970s. New-onset diabetes after solid organ transplantation associated with the use of immunosuppressive therapy (eg, steroids, cyclosporine, tacrolimus, sirolimus, and everolimus) has now been well described. Over the years, it has undergone changes in nomenclatures including steroid diabetes, posttransplant diabetes mellitus, new-onset diabetes mellitus, transplant-associated hyperglycemia, and most recently, new-onset diabetes after transplantation (NODAT). NODAT is a complex metabolic disorder characterized by a relative or absolute impairment in insulin secretion, along with varying degrees of peripheral insulin resistance. In essence, NODAT resembles type 2 diabetes and the diagnosis may be delayed or unrecognized. Indeed, over the years, the precise incidence of NODAT has been difficult to determine due to the lack of standard criteria defined for the condition. In 2003, the International Expert Panel consisting of experts from both the transplant and diabetes fields set forth the International Consensus Guidelines for the diagnosis and management of NODAT. ${ }^{2,3}$ It was recommended that the definition and diagnosis of NODAT be based on the definition of diabetes mellitus and impaired glucose tolerance (IGT) described 
by the World Health Organization (WHO). ${ }^{3,4}$ It is noteworthy that while the 2003 International Consensus Guidelines defined normal fasting plasma glucose (FPG) as a plasma glucose of $<110 \mathrm{mg} / \mathrm{dL}(6.1 \mathrm{mmol} / \mathrm{L})$, the 2003 American Diabetes Association (ADA) expert committee had lowered the diagnostic threshold for impaired FPG to $\geq 100 \mathrm{mg} / \mathrm{dL}$ (5.6 mmol/L). The 2010 updated ADA consensus report included an $\mathrm{A} 1 \mathrm{C}$ level of $\geq 6.5 \%$ as an alternative diagnostic criterion for diabetes mellitus in the general population based on the observed association between A1C level and the risk for future development of retinopathy. The current WHO and ADA guidelines for the diagnosis of prediabetic states (impaired fasting glucose [IFG] and IGT) and diabetes mellitus are provided in Table 1.

Studies in the general population have demonstrated that individuals with IFG, IGT, and/or an A1C value between $5.7 \%$ to $6.4 \%$ are at increased risk for future development

Table I WHO and ADA criteria for the diagnosis of diabetes mellitus

Criteria for the diagnosis of DM

Any one of the following:

I. Classic symptoms of DMa + random PG concentrations $\geq 200 \mathrm{mg} / \mathrm{dL}$ (II.I mM)

2. $F P G \geq 126 \mathrm{mg} / \mathrm{dL}(7.0 \mathrm{mM})$. Fasting is defined as no caloric intake for $\geq 8$ hours

3. 2-hour PG $\geq 200 \mathrm{mg} / \mathrm{dL}$ (1 $1.1 \mathrm{mM}$ ) during an OGTT

4. $A I C^{c} \geq 6.5 \%$

In the absence of unequivocal hyperglycemia accompanied by acute metabolic decompensation, criteria $2-4$ must be confirmed by repeat testing on another day.

Criteria for normal FPG and IFG or IGT

- FPG WHO criteria

FPG $<110 \mathrm{mg} / \mathrm{dL}(6.1 \mathrm{mM})=$ normal fasting glucose

FPG $\geq 110 \mathrm{mg} / \mathrm{dL}(6.1 \mathrm{mM})$ and $<126 \mathrm{mg} / \mathrm{dL}(7.0 \mathrm{mM})=\mathrm{IFG}$

2003 ADA consensus

FPG $<100 \mathrm{mg} / \mathrm{dL}(5.6 \mathrm{mM})=$ normal fasting glucose

FPG $\geq 100 \mathrm{mg} / \mathrm{dL}(5.6 \mathrm{mM})$ and $<126 \mathrm{mg} / \mathrm{dL}(7.0 \mathrm{mM})=\mathrm{IFG}$

OR

- OGTT

2-hour PG $<140 \mathrm{mg} / \mathrm{dL}(7.8 \mathrm{mM})=$ normal glucose tolerance

2-hour PG $\geq 140 \mathrm{mg} / \mathrm{dL}(7.8 \mathrm{mM})$ and $<200 \mathrm{mg} / \mathrm{dl}(\mathrm{I} . \mathrm{I} \mathrm{nM})=$ IGT

Prediabetic states based on AIC level

2010 ADA consensus: $5.7 \%-6.4 \%$

International expert committee: $6.0 \%-6.4 \%$

Notes: aClassic symptoms of DM include polyuria, polydipsia, and unexplained weight loss; ' $\mathrm{O} O \mathrm{GTT}$ : the test should be performed as described by WHO, using a glucose load containing equivalent of $75 \mathrm{~g}$ anhydrous glucose dissolved in water; 'AIC should be performed using a method certified by the National Glycohemoglobin Standardization Program (NGSP) and standardized to the Diabetes Control and Complications Trial (DCCT) reference assay.

Abbreviations: WHO, World Health Organization; ADA, American Diabetes Association; DM, diabetes mellitus; PG, plasma glucose; FPG, fasting plasma glucose; IFG, impaired fasting glucose; IGT, impaired glucose tolerance; OGTT, oral glucose tolerance test. of diabetes. Similar to the nontransplant settings, impaired glucose metabolism in the pre- and/or posttransplant period has been suggested to be a predictive risk factor for the development of NODAT. However, studies investigating the best screening or predictive tool for identifying patients at risk for developing NODAT early after transplantation are lacking. In this article, an overview of the literature on the utilization of currently available glycemic tests to predict or detect subclinical NODAT are discussed. Simple diabetes-prediction models that incorporate clinical and/or laboratory risk factors are also presented, followed by the authors' perspective on the utility of various glycemic tests and diabetes-prediction models in the screening and diagnosis of NODAT.

\section{Literature overview on the utility of FPG, AIC, and/or an oral glucose tolerance test}

\section{The utility of FPG and OGTT in the prediction of NODAT development and as a screening tool}

\section{Glycemic testing in the early posttransplant period (fifth posttransplant day)}

Kuypers et $\mathrm{a}^{4}$ evaluated the utility of determining FPG levels and performing an oral glucose tolerance test (OGTT) in the early posttransplantation period for the prediction of NODAT development. The 2003 ADA criteria were used to define IGT, IFG, and diabetes mellitus. NODAT was defined as the uninterrupted need for glucose-lowering therapy for at least 3 months following transplantation. Renal allograft recipients with pre-existing diabetes mellitus were excluded from the study. All patients in the study completed an OGTT 5 days after transplantation, as stipulated by the WHO. In total, 359 eligible de novo renal transplant recipients were enrolled in the study. At a mean follow-up of $42.8 \pm 16.9$ months, 64 patients (17.8\%) had developed NODAT. A normal (vs diabetic) OGTT at 5 days after transplantation was associated with a reduced risk of NODAT (odds ratio, $0.03 ; P=0.0002$ ). A similar risk reduction was conferred by a normal (vs diabetic) FPG level on day 5 (odds ratio, $0.06 ; P \leq 0.0001$ ). The OGTT on day 5 had better sensitivity ( $93.4 \%$ vs $21.6 \%$ ) and a higher negative predictive value $(97.6 \%$ vs $89.1 \%$ ) than FPG test on day 5, but poorer specificity ( $71.9 \%$ vs $97.6 \%)$ and a lower positive predictive value $(47.2 \%$ vs $61.5 \%)$. For transplant recipients who developed NODAT very early following transplantation, the concern arose that the OGTT on day 5 served merely as a diagnostic rather than a predictive 
tool. However, a multivariate analysis involving only those who developed NODAT 2 or more weeks after the OGTT revealed a similarly significant association between a normal OGTT and a reduced risk for "delayed" NODAT. The results of the study suggested that a normal FPG (vs diabetic) and a normal OGTT (vs diabetic) at 5 days after transplantation seem to identify recipients at reduced risk for NODAT, at least among white subjects $(91.4 \%$ of the study population were white, $1.4 \%$ were black, and Hispanics were absent). These findings remain to be validated in patients of other ethnicities. $^{5}$

A Spanish study by Rodrigo et $\mathrm{al}^{6}$ also examined the predictive value of a fifth-day posttransplantation FPG. Of 282 previously nondiabetic patients, 46 (16.3\%) developed NODAT by the 1-year follow-up. A fifth day $\mathrm{FPG} \geq 126 \mathrm{mg} / \mathrm{dL}$ was associated with a more than fourfold increase in NODAT risk (relative risk, 4.784 ; $95 \%$ confidence interval [CI]: $2.121-10.788 ; P=0.002)$. The positive and negative predictive value of a fifth day FPG $\geq 126 \mathrm{mg} / \mathrm{dL}$ for predicting NODAT at 1 -year were $40 \%$ and $89.4 \%$, respectively. The negative predictive value of nearly $90 \%$ suggested that a nondiabetic FPG may identify patients who are at lower risk for developing NODAT and therefore require less intensive screening in the future.

\section{Glycemic testing after the first 6 months posttransplantation}

Armstrong et $\mathrm{al}^{7}$ were among the first to examine the predictive power of FPG with respect to 2-hour blood glucose. A total of 200 previously nondiabetic renal transplant recipients who were more than 6 months posttransplantation underwent a standard 2-hour OGTT. Patients with FPG $<126 \mathrm{mg} / \mathrm{dL}$ (7.0 $\mathrm{mmol} / \mathrm{L} ; \mathrm{n}=188)$ underwent an OGTT. Receiveroperating characteristics (ROC) analyses were used to evaluate the optimal level of FPG that was predictive of NODAT (2-hour blood glucose $\geq 200 \mathrm{mg} / \mathrm{dL} ; 11.0 \mathrm{mmol} / \mathrm{L}$ ) and IGT (2-hour blood glucose of 140-200 mg/dL or $7.8-11.0 \mathrm{mmol} / \mathrm{L})$. Forty-two percent of study subjects were found to have an abnormal OGTT (NODAT in 12\% and IGT in $30 \%$ ). The optimal FPG that was predictive of NODAT was $101 \mathrm{mg} / \mathrm{dL}(5.6 \mathrm{mmol} / \mathrm{L}$; area under the curve, 0.70 ; sensitivity, $64 \%$; specificity, $67 \%$; positive predictive value, 20\%; negative predictive value, 93\%). The optimal FPG that was predictive of IGT was less well defined (area under the curve, 0.54). The prevalence of NODAT was higher by OGTT than by FPG alone (17\% vs $6 \% ; P<0.0001)$. However, it is noteworthy that more than $80 \%$ of the study population was white. Inclusion of more patients with diverse ethnic background might have altered the reported prevalence of NODAT and IGT. Nonetheless, results from the study suggested that FPG may not be the optimal screening or diagnostic tool for NODAT or IGT due to its lack of sensitivity and specificity. Hence, the authors proposed that OGTT should be considered as a routine screening test in all renal transplant recipients.

In a prospective study designed to evaluate the value of OGTT for risk-stratifying patients for NODAT, Sharif et $\mathrm{al}^{8}$ demonstrated that among 122 renal transplant recipients without diabetes who had two FPG level measurements within the range of 100-125 $\mathrm{mg} / \mathrm{dL}(5.6-6.9 \mathrm{mmol} / \mathrm{L})$ more than 6 months after transplantation, OGTT revealed that $10 \%$ had overt diabetes mellitus, 9\% had IGT alone, 18\% had IFG alone (all defined by WHO criteria), and 14\% had combined IFG and IGT. In agreement with most studies, this study demonstrated that FPG underestimates the prevalence of NODAT and IGT and suggested the routine use of OGTT in risk stratifying renal transplant recipients for the development of NODAT.

\section{The utility of FPG and AIC in the prediction of NODAT development and as a screening tool}

Hoban et $\mathrm{al}^{9}$ first described the utility of $\mathrm{A} 1 \mathrm{C}$ in the detection of subclinical NODAT in recipients of kidney transplant recipients. The study consisted of 199 previously nondiabetic adult kidney transplant recipients who were $\geq 3$ months posttransplant (one subject was enrolled at 73 days posttransplant). All study subjects were required to have a history of normal FPG (not defined) prior to study entry. Pregnant patients, patients on dialysis and those with recent blood transfusion or blood loss that might affect $\mathrm{A} 1 \mathrm{C}$ measurements were excluded. A normal A1C was defined as an $\mathrm{A} 1 \mathrm{C}$ of $<6.1 \%$. Of 199 patients studied, 20 (10.1\%) were found to have an $\mathrm{A} 1 \mathrm{C} \geq 6.1 \%$, six of whom had both elevated A1C and new-onset elevated FPG at study entry despite a history of normoglycemia. In clinical follow-up (6.9 years posttransplant), 13 of the 20 (all six patients with both elevated FPG and A1C) and seven of the 14 patients with only elevated $\mathrm{A} 1 \mathrm{C}$ had medical intervention for diabetes or glucose intolerance. Of the six patients with elevated A1C and FPG, five were eventually diagnosed with diabetes mellitus at long-term follow-up. Of the 14 patients with elevated $\mathrm{A} 1 \mathrm{C}$ and normal screening FPG, three were diagnosed with diabetes mellitus and four with glucose intolerance. Notably, the odds of African Americans having an elevated $\mathrm{A} 1 \mathrm{C}$ were 2.8 times higher than those of other 
races, with $19.4 \%$ of African Americans having elevated A1C compared with $8 \%$ of their non-African American counterparts. However, multivariate logistic regression analysis demonstrated that high normal FPG was significantly associated with an elevated A1C $(P=0.003)$, whereas an ethnicity effect was only marginally significant when adjusted for FPG $(P=0.08)$. The investigators concluded that A1C level was a more sensitive test than FPG in detecting NODAT and further validated this recommendation in African Americans. Nonetheless, their study was not without shortcomings. The rationale for using an A1C level of $\geq 6.1 \%$ to screen for NODAT was not defined and the number of patients undergoing the gold standard OGTT was not stated. Furthermore, African Americans predominated the study population $(81.9 \%)$. Hence, the use of $\mathrm{A} 1 \mathrm{C}$ as a screening or diagnostic tool in the setting of organ transplantation has yet to be validated.

\section{The utility of FPG and AIC in the selection of patients to undergo OGTT}

In a single center study, Valderhaug et $\mathrm{al}^{10}$ aimed to assess the accuracy of FPG and A1C for the selection of patients who should undergo a diagnostic OGTT 10 weeks after renal transplantation. Among the 1637 previously nondiabetic renal transplant recipients who were prospectively examined 10 weeks after transplantation, 66 patients were found to have manifest NODAT and were excluded from oral glucose tolerance testing. The remaining 1571 patients with previously normal FPG underwent an OGTT. Of these, 213 (14\%) were diagnosed with NODAT, $51 \%$ of whom $(n=109)$ were identified by 2 -hour $\mathrm{PG} \geq 11.1 \mathrm{mmol} / \mathrm{L}$ alone, and $17 \%$ ( $\mathrm{n}=35$ ) by FPG alone (FPG $\geq 7.0 \mathrm{mmol} / \mathrm{L})$. Sixty-nine patients $(32 \%)$ fulfilled both criteria for NODAT. To assess the diagnostic accuracy of FPG and A1C to predict a 2-hour PG $>11.1 \mathrm{mmol} / \mathrm{L}$, an analysis involving a subgroup of patients with a FPG of $<7 \mathrm{mmol} / \mathrm{L}$ and available A1C levels ( $n=929)$ was performed. Receiver operating characteristic analysis revealed an area under the curve of 0.761 (95\% confidence interval [CI]: 0.714-0.809) for FPG and 0.817 (95\% CI: 0.758-0.876) for A1C. Performing an OGTT on patients with a $\mathrm{FPG} \geq 5.3 \mathrm{mmol} / \mathrm{L}$ or $\mathrm{A} 1 \mathrm{C} \geq 5.8 \%$ predicted diabetes with $81 \%$ and $83 \%$ sensitivity, requiring $49 \%$ and $41 \%$ of the patients to be tested, respectively. The combined criteria of $\mathrm{FPG} \geq 5.0 \mathrm{mmol} / \mathrm{L}$ and $\mathrm{A} 1 \mathrm{C} \geq 5.7 \%$ provided similar sensitivity (79\%) from testing only $29 \%$ of the population. The authors concluded that OGTT should be considered in patients with a FPG between 5.3-6.9 mmol/L or glycosylated hemoglobin $>5.8 \%$ or in those with combined
$\mathrm{FPG}>5.0 \mathrm{mmol} / \mathrm{L}$ and $\mathrm{A} 1 \mathrm{C}>5.7 \%$. However, the authors acknowledged that $95 \%$ of the study population were white and the study results might not be valid for patients of other ethnicities.

\section{The utility of FPG, AIC, and OGTT in the prediction of NODAT development and as a screening tool: summary of the literature}

A literature review suggests that similar to the general population, the 2-hour OGTT diagnostic criteria may be more sensitive in identifying patients with IGT or NODAT than those set for FPG.

The introduction of $\mathrm{A} 1 \mathrm{C}$ as an additional optional diagnostic criterion for diabetes mellitus in the general population has sparked interest in its use as a screening and diagnostic tool in renal transplant recipients. One single-center study suggested that A1C level was a more sensitive test than FPG in detecting NODAT, particularly in African Americans (as discussed in the previous section). However, the majority of patients in the study were African Americans. The utility of $\mathrm{A} 1 \mathrm{C}$ as the routine screening or diagnostic tool in identifying patients with NODAT has yet to be validated in patients of other ethnic backgrounds. Clinical studies evaluating the utility of FPG, A1C, and OGTT in the prediction of NODAT development and as a screening tool are summarized in Table 2.

\section{Predictive diagnostic tools for NODAT development: perioperative hyperglycemia and diabetes prediction models}

\section{New-onset hyperglycemia in the immediate postoperative period}

Recently, new-onset hyperglycemia in the immediate postoperative period (inpatient hyperglycemia) defined as bedside capillary glucose of $\geq 200 \mathrm{mg} / \mathrm{dL}$ on at least one measurement, or the administration of insulin therapy at any time during the hospital stay, has been suggested to be predictive of future NODAT risk. ${ }^{11}$ Among 377 primary kidney transplant recipients with at least 1-year follow-up, NODAT developed in $4 \%$ of patients without inpatient hyperglycemia, $18 \%$ of patients with inpatient hyperglycemia, but not treated with insulin, and in $30 \%$ of patients who were diagnosed with inpatient hyperglycemia and treated with insulin. Further studies are required to confirm the utility of new-onset hyperglycemia in the 
Table 2 Clinical studies evaluating the utility of FPG, AIC, and OGTT in the screening and diagnosis of NODAT

\begin{tabular}{|c|c|c|c|c|}
\hline Study protocols & $\begin{array}{l}\text { Demographic } \\
\text { characteristics }\end{array}$ & Study results & Conclusions & References \\
\hline $\begin{array}{l}\text { FPG and OGTT } \\
\mathrm{N}=359 \\
\text { All patients completed } \\
\text { OGTT } 5 \text { days postTx } \\
\text { Mean follow-up } \\
42.8 \pm 16.9 \text { months }\end{array}$ & $\begin{array}{l}\text { White } 91.4 \% \\
\text { Blacks } 1.4 \% \\
\text { Arabic } 7.2 \%\end{array}$ & $\begin{array}{l}\text { - } 17.8 \% \text { developed NODAT } \\
\text { - A normal (vs diabetic) OGTT at day } 5 \text { postTx } \\
\text { was associated with } \downarrow \text { NODAT risk } \\
(\mathrm{OR}=0.03 ; P=0.0002) \\
\text { Sensitivity, } 93.4 \% \text {; Specificity, } 71.9 \% \\
\text { - A normal (vs diabetic) FPG on day } 5 \text { postTx } \\
\text { was associated with } \downarrow \text { NODAT risk } \\
(\text { OR }=0.06 ; P<0.000 \text { I) } \\
\text { Sensitivity, } 21.6 \% \text {; Specificity, } 97.6 \%\end{array}$ & $\begin{array}{l}\text { A normal FPG } \\
\text { (vs diabetic) and a } \\
\text { normal OGTT } \\
\text { (vs diabetic) at } 5 \text { days } \\
\text { postTx seems to } \\
\text { identify patients } \\
\text { at } \downarrow \text { NODAT risk }\end{array}$ & $\begin{array}{l}\text { Kuypers } \\
\text { et a }\left.\right|^{4}\end{array}$ \\
\hline $\begin{array}{l}\text { FPG } \\
\mathrm{N}=282 \text { (patients with } \\
\text { graft survival }>I \text { year) } \\
\text { FPG at day } 5 \text { postTx }\end{array}$ & Spanish study & $\begin{array}{l}\text { - } 16.3 \% \text { developed NODAT at month } 12 \\
\text { - A fifth day FPG } \geq 126 \mathrm{mg} / \mathrm{dL} \text { was associated } \\
\text { with a more than fourfold increase in NODAT } \\
\text { risk (relative risk: } 4.784 ; P=0.002 \text { ) } \\
\text { - The positive and negative predictive values of a fifth } \\
\text { day FPG } \geq 126 \mathrm{mg} / \mathrm{dL} \text { for predicting NODAT } \\
\text { at I-year were } 40 \% \text { and } 89.4 \% \text {, respectively }\end{array}$ & $\begin{array}{l}\text { A negative predictive } \\
\text { value of } 89.4 \% \text { suggests } \\
\text { that a FPG }<126 \mathrm{mg} / \mathrm{dL} \\
\text { may identify patients } \\
\text { with a low risk } \\
\text { (near } 10 \% \text { ) for } \\
\text { NODAT }\end{array}$ & $\begin{array}{l}\text { Rodrigo } \\
\text { et } \mathrm{al}^{6}\end{array}$ \\
\hline $\begin{array}{l}\text { FPG and OGTT } \\
\mathrm{N}=188>6 \text { months postTx, } \\
\text { OGTT performed in patients } \\
\text { with FPG }<7.0 \mathrm{mmol} / \mathrm{L}\end{array}$ & White $>90 \%$ & $\begin{array}{l}\text { ROC analyses } \\
\text { - Optimal FPG predictive of NODAT: } \\
\text { I0I mg/dL; } 5.6 \text { mmol/L (AUC = } 0.70 \text {; } \\
\text { sensitivity } 64 \% \text {; specificity } 67 \% \text {, positive } \\
\text { predictive } 20 \% \text {; negative predictive } 93 \% \text { ) } \\
\text { - Optimal FPG predictive of IGT less } \\
\text { well-defined (AUC = 0.54) } \\
\text { - Prevalence of NODAT (OGTT vs FPG } \\
\text { I7\% vs } 6 \% \text {, respectively; } P<0.000 \text { I) }\end{array}$ & $\begin{array}{l}\text { FPG may not be the } \\
\text { optimal screening or } \\
\text { diagnostic tool due } \\
\text { to lack of sensitivity } \\
\text { and specificity } \\
\text { OGTT should be } \\
\text { considered as a routine } \\
\text { screening test in all renal } \\
\text { transplant recipients }\end{array}$ & $\begin{array}{l}\text { Armstrong } \\
\text { et } \mathrm{al}^{7}\end{array}$ \\
\hline $\begin{array}{l}\text { FPG and OGTT } \\
\mathrm{N}=122>6 \text { months postTx } \\
\text { OGTT performed in patients } \\
\text { with two FPG values between } \\
5.6-6.9 \mathrm{mmol} / \mathrm{L}\end{array}$ & $\begin{array}{l}\text { White } 96 \% \\
\text { Asian } 3 \% \\
\text { Afro- } \\
\text { Caribbean } 1 \%\end{array}$ & $\begin{array}{l}\text { OGTT revealed I0\% had overt DM, } \\
9 \% \text { IGT alone, I8\% IFG alone, } \\
\text { I4\% combined IFG and IGT }\end{array}$ & $\begin{array}{l}\text { FPG underestimates } \\
\text { IGT and NODAT } \\
\text { prevalence } \\
\text { Routine use of OGTT is a } \\
\text { valuable clinical tool to risk } \\
\text { stratify patient for NODAT }\end{array}$ & $\begin{array}{l}\text { Sharif } \\
\text { et } \mathrm{al}^{8}\end{array}$ \\
\hline $\begin{array}{l}\text { FPG and AIC } \\
N=199 \geq 3 \text { months postTx } \\
\text { All patients had a history of } \\
\text { normal FPG prior to study } \\
\text { Normal AIC defined } \\
\text { as }<6.1 \%\end{array}$ & $\begin{array}{l}\text { African } \\
\text { Americans } 81.9 \%\end{array}$ & $\begin{array}{l}\text { - Twenty (I0.I\%) had AIC } \geq 6.1 \% \text { ( } 6 \text { of whom } \\
\text { had both } \uparrow A I C \text { and new onset } \uparrow F P G \text { at study } \\
\text { entry) and I4 had } \uparrow A I C \text { only } \\
\text { - Of the } 6 \text { patients with both } \uparrow A I C \text { and new } \\
\text { onset } \uparrow F P G, 5 \text { were diagnosed with NODAT } \\
\text { - Of the I4 patients with } \uparrow A I C \text { only, } 3 \text { were } \\
\text { diagnosed with NODAT and } 4 \text { with } \\
\text { glucose intolerance } \\
\text { - The odds of African Americans having } \uparrow A I C \\
\text { were } 2.8 \text { times higher than other races } \\
\text { - High normal FPG was significantly associated } \\
\text { with an } \uparrow A I C(P=0.003 \text { ) } \\
\text { - Race effect marginally significant when adjusted } \\
\text { for FPG }(P=0.08)\end{array}$ & $\begin{array}{l}\text { AIC level was a more } \\
\text { sensitive test than FPG } \\
\text { in detecting NODAT } \\
\text { AIC testing should be } \\
\text { considered as a } \\
\text { screening test for } \\
\text { NODAT, especially } \\
\text { in African Americans }\end{array}$ & $\begin{array}{l}\text { Hoban } \\
\text { et al }{ }^{9}\end{array}$ \\
\hline $\begin{array}{l}\text { FPG, AIC, and OGTT } \\
\mathrm{N}=929 @ \text { I0-week postTx } \\
\text { Patients who had both } \\
\text { FPG }<7.0 \mathrm{mmol} / \mathrm{L} \text { and } \mathrm{AIC} \\
\text { levels available were } \\
\text { evaluated }\end{array}$ & White $95 \%$ & $\begin{array}{l}\text { ROC analysis } \\
\text { - FPG: AUC } 0.76 \mathrm{I}(95 \% \mathrm{Cl}: 0.7 \mathrm{I} 4-0.809) \\
\text { - AIC: AUC } 0.817 \text { ( } 95 \% \mathrm{Cl}: 0.758-0.876) \\
\text { - Performing OGTT on patients with } \\
\text { FPG } \geq 5.3 \mathrm{mmol} / \mathrm{L} \text { or } \mathrm{AIC} \geq 5.8 \% \text { predicted } \\
\text { NODAT with } 81 \% \text { and } 83 \% \text { sensitivity, requiring } 49 \% \\
\text { and } 41 \% \text { of the patients to be tested, respectively } \\
\text { - Combined criterion of FPG } \geq 5.0 \mathrm{mmol} / \mathrm{L} \text { and } \\
\text { AIC } \geq 5.7 \% \text { provided a sensitivity of } 79 \% \text { from } \\
\text { testing } 29 \% \text { of the population }\end{array}$ & $\begin{array}{l}\text { OGTT should be } \\
\text { considered in patients } \\
\text { with FPG between } \\
5.3-6.9 \mathrm{mmol} / \mathrm{L} \text { or } \\
\text { AIC }>5.8 \% \\
\text { or } \\
\text { In those with combined } \\
\text { FPG } \geq 5 \mathrm{mmol} / \mathrm{L} \text { and } \\
\text { AIC } \geq 5.7 \%\end{array}$ & $\begin{array}{l}\text { Valderhaugh } \\
\text { et al }{ }^{\prime 0}\end{array}$ \\
\hline
\end{tabular}

Abbreviations: $\mathrm{Cl}$, confidence interval; DM, diabetes mellitus; FPG, fasting plasma glucose; OGTT, oral glucose tolerance test; PostTx, posttransplant; ROC, receiveroperating characteristic; AUC, area under the curve. 
immediate postoperative period in the screening and diagnosis of NODAT.

\section{Diabetes prediction models}

\section{Prediction of NODAT before kidney transplant}

While most studies designed to predict the development of NODAT predominantly focus on the assessment of actual glucose metabolism, studies in the general population suggested that simple prediction models that incorporate clinical and/or metabolic risk factors (eg, age, family history of type 2 diabetes, body mass index [BMI], blood pressure, high-density lipoprotein [HDL], triglycerides, and IFG) to generate a prediction score may be more effective in predicting diabetes than complex models involving the analysis of glucose metabolism such as OGTT, insulin sensitivity, and/or insulin resistance. Similar comparative studies in the transplant settings are lacking. Nonetheless, studies evaluating the predictive values of diabetic prone clinical factors are emerging.

In one-single center study consisting of 318 nondiabetic patients who subsequently received a kidney transplant, Chakkera et a ${ }^{12}$ demonstrated that a simple risk score utilizing the sum of seven dichotomized pretransplant risk factors is comparable with that of a standard multivariate model using continuous variables in predicting NODAT (areas under the ROC for predicting NODAT were between 0.7 and 0.72 for all models tested). A score of $0-7$ calculated from pretransplant age, family history of type 2 diabetes, BMI, FPG and triglycerides, use of gout medications, and predicted use of posttransplant corticosteroid (nontransplant or immunological indications) were predictive of the incidence of NODAT at 1-year posttransplant. The risk of NODAT ranged from $13 \%$, for a score of 0 to 1 , to $56 \%$, for a score of $\geq 4$ (Table 3). NODAT was defined as having an $\mathrm{A} 1 \mathrm{C} \geq 6.5 \%, \mathrm{FPG} \geq 126 \mathrm{mg} / \mathrm{dL}$, or the need for dietary modification or medical therapy for diabetes between 1 month and 1 year posttransplant.

In a different study consisting of 120 nondiabetic patients who later received a kidney transplant, Caillard et $\mathrm{al}^{13}$ demonstrated that pretransplant IGT, age (more than or less than 50 years), and type of nephropathy (presence or absence of adult polycystic kidney disease) are helpful tools for identifying patients at risk for NODAT. Multivariate analysis demonstrated that the risk of developing NODAT increased 2.4-fold (0.8-7) in recipients with one risk factor $(P=0.1), 5.2$-fold $(1.8-15)$ in recipients with two risk factors $(P=0.02)$, and 14-fold (3-67) in recipients with three risk factors $(P=0.01)$. The presence of two or three of these pretransplant risk factors enabled prediction of NODAT with a sensitivity of $48 \%$, specificity of $85 \%$, positive predictive value of $55 \%$, and negative predictive value of $83 \%$.

In a retrospective analysis consisting of 640 nondiabetic renal transplant recipients, Bayer et $\mathrm{al}^{14}$ demonstrated that the prevalence of NODAT at 1 year increased with increasing number of metabolic syndrome score $(0,0 \% ; 1,24 \%$; $2,29 \% ; 3,31 \% ; 4,35 \% ; 5,74 \% ; P=0.001)$. Multivariate analysis incorporating the individual metabolic syndrome components as covariates demonstrated that only lowdensity lipoprotein was independently associated with the development of NODAT.

\section{Prediction of NODAT after the first posttransplant year}

In a retrospective study consisting of 191 kidney transplant recipients with at least 1-year posttransplant follow-up, Rodrigo et $\mathrm{al}^{15}$ showed the Framingham Offspring StudyDiabetes Mellitus (FOS-DM) and San Antonio Diabetes Prediction Model (SADPM) scores that predict type 2 diabetes mellitus in the general population ${ }^{16,17}$ can similarly predict NODAT in kidney transplant recipients. The SADPM includes the variables of age, sex, Mexican-American ethnicity, fasting glucose, systolic blood pressure, HDL cholesterol, BMI, and family history of diabetes. The FOS-DM model utilizes overweight/obese, impaired fasting glucose, HDL cholesterol, hypertriglyceridemia, hypertension, and family history of diabetes. ${ }^{18}$ FOS-DM and SADPM scores over the 75 percentile were shown to be associated with a five- and eightfold increase in NODAT risk, respectively, $P<0.001$. The cumulative incidence of NODAT at 6 years was significantly higher for patients over the 75 percen-

Table 3 Association of pretransplant risk score with NODAT development

\begin{tabular}{lll}
\hline Risk score* (0-7) & N (\# of patients) & I-year cumulative incidence of NODAT \\
\hline Low risk (0-1) & 109 & $13 \%$ \\
Intermediate risk (2-3) & 170 & $29 \%$ \\
High risk (4-7) & 39 & $56 \%$ \\
\hline
\end{tabular}

Notes: *A risk score of 0-7 was calculated from seven pretransplant risk factors (age, family history of type 2 diabetes, BMI, FPG, triglycerides, use of gout medications, and predicted use of steroids posttransplant).

Abbreviations: BMI, body mass index; FPG, fasting plasma glucose; NODAT, new-onset diabetes after transplantation. 
tile of both FOS-DM $(10.7 \%$ vs $3.7 \% ; P<0.001)$ and SADPM scores $(11.4 \%$ vs $2.1 \% ; P<0.001)$. The positive and negative predictive values of the FOS-DM score over the 75 percentile were $24.5 \%$ and $92.5 \%$, respectively. The positive and negative predictive values of the SADPM score over the 75 percentile were $31.2 \%$ and $93.7 \%$, respectively. While the low positive predictive values of both scores indicate that they cannot be used to identify the future evolution of an individual patient, the high negative predictive values of the top quartile suggest that both scores can be used to identify the $25 \%$ of kidney transplant recipients with a higher risk for developing NODAT beyond the first year. Notably, the SADPM score detects $25 \%$ of kidney transplant patients with an eightfold risk for NODAT, suggesting that this instrument can be used to define a target population for NODAT prevention programs. The authors proposed a two-step screening model, using the Chakkera algorithm pretransplant $^{11}$ followed by the SADPM or FOS-DM at 1 year posttransplant.

\section{Screening strategies and predictive diagnostic tools for NODAT development: the International Consensus Guidelines and the authors' perspectives}

The 2003 International Consensus Guidelines recommended screening all transplant patients with FPG at least once a week for the first 4 weeks, then at 3, 6, and 12 months, and annually thereafter. Plasma glucose levels should also be randomly monitored at regular intervals, preferably concomitantly with immunosuppressant level testing (for patients' convenience). In those with an intermediate FPG, defined as plasma glucose between 110-125 mg/dL; 6.1-6.9 mmol/L, and normal FPG, defined as FPG $<110 \mathrm{mg} / \mathrm{dL} ; 6.1 \mathrm{mmol} / \mathrm{L}$, a 2-hour OGTT should be considered. ${ }^{2}$

The 2005 updated International Consensus Guidelines recommended screening all individuals, regardless of diabetic status, with FPG at regular intervals and OGTT be performed in those with an intermediate FPG. After the first 3 months posttransplant, A1C testing should be part of the same screening schedule as that of FPG. ${ }^{3}$

Although the 2-hour OGTT diagnostic criteria may be more sensitive in identifying patients with IGT or NODAT than those set for FPG, screening all renal transplant patients with OGTT may be costly and impractical in clinical practice. The 2003 International Consensus Guidelines suggested OGTT in patients with intermediate or normal FPG defined as
FPG $<110 \mathrm{mg} / \mathrm{dL}(6.1 \mathrm{mmol} / \mathrm{L})$. However, the rationale for performing an OGTT in all patients with FPG $<110 \mathrm{mg} / \mathrm{dL}$ $(6.1 \mathrm{mmol} / \mathrm{L})$ was not substantiated and such practice may also entail testing a large number of patients, which may not be feasible.

In the authors' opinion, OGTT should be considered in patients with multiple risk factors for NODAT, whereas FPG or A1C or both can be used to screen or risk stratify patients and should be monitored in all renal transplant recipients at regular intervals. In the case $\mathrm{A} 1 \mathrm{C}$ is used, clinicians are advised to confirm that the assays involved have been standardized and validated. Additionally, it should be noted that $\mathrm{A} 1 \mathrm{C}$ cannot be accurately interpreted within the first 3 months posttransplantation due to various factors including possible blood transfusions in the early posttransplant period and the presence of anemia or impaired graft function. Blood transfusions may render the test invalid while anemia and kidney impairment can directly interfere with the A1C assay. In islet cell transplant recipients, an artifactual reduction in $\mathrm{A} 1 \mathrm{C}$ level has been reported in recipients receiving dapsone for Pneumocystis carinii (P. jiroveci) prophylaxis. ${ }^{19}$ The cause is unknown but a reduction in red cell lifespan or hemolysis or both has been implicated.

The available literature suggests that similar to the nontransplant settings, the risk for developing NODAT appears to follow a continuum across the entire spectrum of subdiabetic glycemic values. Renal transplant recipients with higher surveillance FPG, higher A1C levels, or both, may convey higher NODAT risk compared with those with lower values and are thus justified to undergo OGTT. Whether all patients with new-onset hyperglycemia in the immediate postoperative period, particularly those requiring insulin, should undergo OGTT at long-term follow-up remains to be studied. Similarly, whether diabetes prediction models can be used to incite further diagnostic testing with an OGTT remains to be explored.

Lastly, it should be noted that the International Expert Committee has recently advocated the use of standardized $\mathrm{A} 1 \mathrm{C}$ in the diagnosis of diabetes mellitus in the general population. If $\mathrm{A} 1 \mathrm{C}$ testing is not possible, FPG or 2-hour plasma glucose are considered acceptable alternative diagnostic tools. ${ }^{20}$ In the United States, OGTT has largely been abandoned outside of screening for gestational diabetes, due to its complexity and low reproducibility. ${ }^{21}$ However, in contrast to the nontransplant settings, the use of A1C in the diagnosis of NODAT has not been validated, particularly in the early posttransplant period, due to the presence of multiple confounding factors. Therefore, OGTT has remained the 


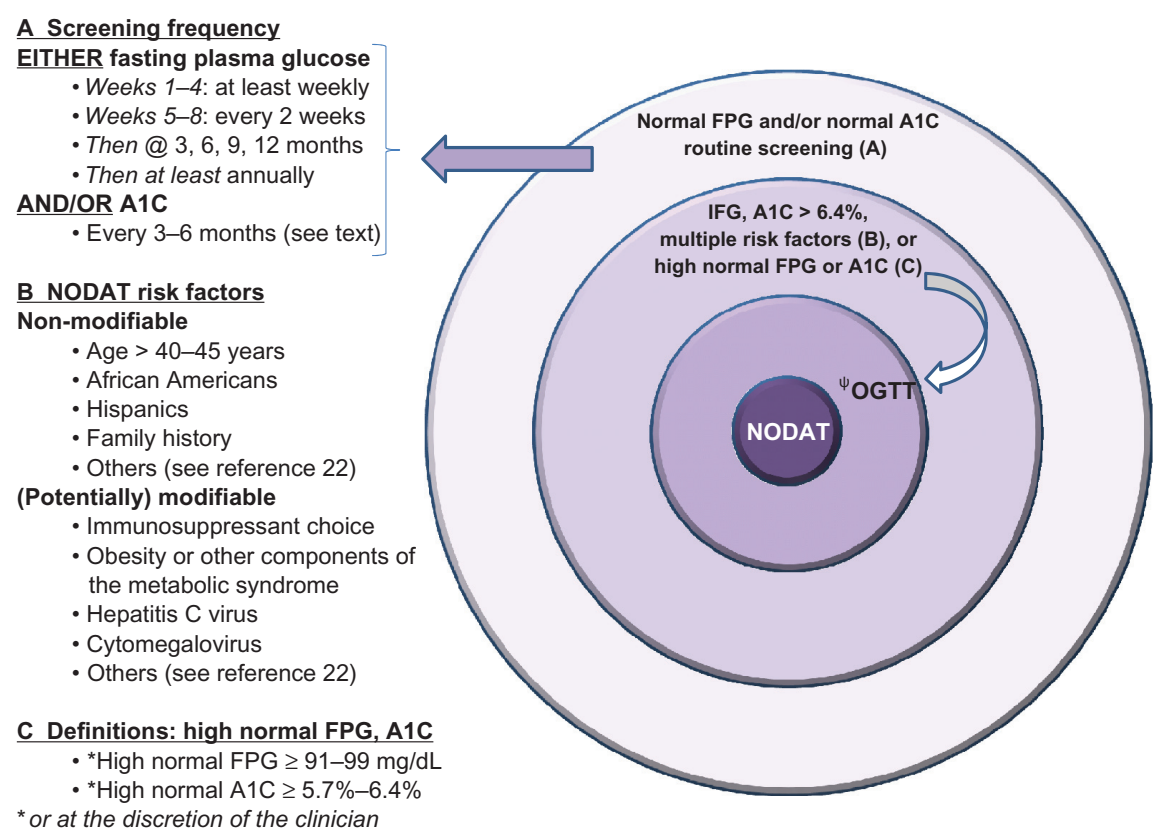

Figure I Targeting new onset diabetes after transplantation (NODAT).

Note: ${ }^{\psi}$ Oral Glucose Tolerance Testing (OGTT) is the current gold standard test for the diagnosis of NODAT.

Abbreviations: FPG, fasting plasma glucose; IFG, impaired fasting glucose; NODAT, new-onset diabetes after transplantation.

gold-standard test for the diagnosis of new-onset diabetes after organ transplantation. A suggested algorithm for NODAT screening is shown in Figure 1.

\section{Disclosure}

The authors report no conflicts of interest in this work.

\section{References}

1. Starlz TE. Experience in Renal Transplantation. Philadelphia: Saunders; 1964:111.

2. Davidson J, Wilkinson A, Dantal J, et al. New-onset diabetes after transplantation: 2003 International Consensus guidelines. Transplantation. 2003;75(10):SS3-SS24.

3. Wilkinson AH, Davidson J, Dotta F, et al. Guidelines for the treatment and management of new-onset diabetes after transplantation. Clin Transplant. 2005;19:291-298.

4. Kuypers DR, Claes K, Bammens B, et al. Early clinical assessment of glucose metabolism in renal allograft recipients: diagnosis and prediction of post-transplant diabetes mellitus (PTDM). Nephrol Dial Transplant. 2008;23:2033-2042.

5. Pham PT, Pham PC. Assessing the risk of post-transplantation diabetes mellitus with an oral glucose tolerance test. Nature Clin Practice. 2008;4(11):600-601.

6. Rodrigo E, Santos L, Pinera C, et al. Early prediction of new-onset diabetes mellitus by fifth-day fasting plasma glucose, pulse pressure, and proteinuria. Transplant Proc. 2011;43(6):2208-2210.

7. Armstrong KA, Prins JB, Beller EM, et al. Should an oral glucose tolerance test be performed routinely in all renal transplant recipients? Clin J Am Soc Nephrol. 2006;1:100-108.

8. Sharif A, Moore RH, Baboolal K. The use of oral glucose tolerance tests to risk stratify for new-onset diabetes after transplantation: an underdiagnosed phenomenon. Transplantation. 2006;82: $1667-1672$.
9. Hoban R, Gielda B, Temkit M, et al. Utility of $\mathrm{HbA}_{1 c}$ in the detection of subclinical post renal transplant diabetes. Transplantation. 2006;81(3):379-383.

10. Valderhaug TG, Jensen T, Hartmann A, et al. Fasting plasma glucose and glycosylated hemoglobin in the screening for diabetes mellitus after renal transplantation. Transplantation. 2009;88:429-434.

11. Chakkera HA, Knowler WC, Devarapalli Y, et al. Relationship between inpatient hyperglycemia and insulin treatment after kidney transplantation and future new onset diabetes mellitus. Clin J Am Soc Nephrol. 2010;5:1669-1675.

12. Chakkera HA, Weil EJ, Swanson CM, et al. Pretransplant risk score for New-Onset Diabetes After Kidney Transplantation. Am J Transplant. 2011;34:2141-2145.

13. Caillard S, Eprinchard L, Perrin P, et al. Incidence and risk factors of glucose metabolism disorders in kidney transplant recipients: Role of systematic screening by oral glucose tolerance test. Transplantation. 2011;91(7):757-764.

14. Bayer ND, Cochetti PT, Kumar MSA, et al. Association of metabolic syndrome with development of new onset diabetes after transplant. Transplantation. 2010;90(8):861-866.

15. Rodrigo E, Santos L, Pinera C, et al. Prediction at first year of incident new-onset diabetes after kidney transplantation by risk prediction models. Diabetes Care. 2012;35:471-473.

16. Wilson PWF, Meigs JB, Sullivan L, et al. Prediction of incident diabetes mellitus in middle-aged adults: the Framingham Offspring Study. Arch Intern Med. 2007;167:1068-1074.

17. Stern MP, Williams K, Haffner SM. Identification of persons at high risk for type 2 diabetes mellitus: do we need the oral glucose tolerance test? Ann Intern Med. 2002;136:575-581.

18. Mann DM, Bertoni AG, Shimbo D, et al. Comparative validity of 3 diabetes mellitus risk prediction scoring models in a multiethnic US cohort: the Multi-Ethnic Study of Atherosclerosis. Am J Epidemiol. 2010;171(9):980-988.

19. Froud T, Faradji RN, Monroy K, et al. Dapsone-induced artifactual $\mathrm{A} 1 \mathrm{C}$ reduction in islet transplant recipients. Transplantation. 2007;83(6):824-825. 
20. The International Expert Committee. International Expert Committee report on the role of the A1C assay in the diagnosis of diabetes. Diabetes Care. 2009;32(7):1327-1334.

21. Inzucchi SE. Diagnosis of diabetes. N Engl J Med. 2012;367(6): $542-550$.
22. Pham PT, Pham PM, Pham SV, et al. New onset diabetes after transplantation: an overview. Diabetes Metab Syndro Obes. 2011;4:175-186.

Diabetes, Metabolic Syndrome and Obesity: Targets and Therapy

\section{Publish your work in this journal}

Diabetes, Metabolic Syndrome and Obesity: Targets and Therapy is an international, peer-reviewed open-access journal committed to the rapid publication of the latest laboratory and clinical findings in the fields of diabetes, metabolic syndrome and obesity research. Original research, review, case reports, hypothesis formation, expert opinion and commentaries are all considered for publication. The manuscript management system is completely online and includes a very quick and fair peer-review system, which is all easy to use. Visit http://www.dovepress.com/testimonials.php to read real quotes from published authors.

Submit your manuscript here: http://www.dovepress.com/diabetes-metabolic-syndrome-and-obesity-targets-and-therapy-journal 